\title{
A case of recurrently sexually transmitted urinary tract infection
}

\author{
W AL-WALI, J M T HAMILTON-MILLER, S JOSHI, W BRUMFITT \\ From the Department of Medical Microbiology and the Urinary Infection Clinic, The Royal Free Hospital and \\ School of Medicine, London, UK
}

SUMMARY A lady with recurrent urinary infection associated with sexual intercourse with her husband is described. The source of the infection was from the husband's chronically infected prostate.

Sexual intercourse is a known predisposing factor in causing urinary infections in women.' It is believed that the bacteria colonising the female's urethra are mechanically pushed up to the bladder. There have also been some reported cases of males acquiring urinary infection from their female sexual partners. ${ }^{23}$ We report here a case of recurrently sexually acquired urinary infection in a female, derived from her husband who had a source of infection in the form of chronic prostatitis.

\section{Report of a case}

A 41 year old woman was referred to the Urinary Infection Clinic, Royal Free Hospital, complaining of recurring urgency, frequency, urethral soreness and suprapubic discomfort. Her symptoms started 3 years previously, coinciding with her second marriage. During the last 2 years the attacks became worse, and in the last 12 months she had had more than 10 episodes. Her symptomatic episodes usually occurred 48 hours after intercourse.

When seen, the patient was very tense and had a butterfly rash on her face which appeared only when she was subjected to stressful situations. The rash was not acne rosacea and systemic lupus erythematosis was excluded by the appropriate immunological investigations by the Rheumatology Department. She had no renal tenderness or enlargement but had mild suprapubic tenderness. An MSU showed WBC 20/ $\mathrm{mm}^{3}$ with more than $10^{5}$ organisms $/ \mathrm{ml}$ of Escherichia coli which was fully sensitive to antibiotics. Her chemical pathology and haematology profiles were normal.

Address for reprint requests: Dr W Al-Wali, Department of Medical Microbiology, Royal Free Hospital, London NW3 2QG, UK

Accepted for publication 14 September 1989
The patient was treated with pivampicillin $500 \mathrm{mg}$ b.d. for 5 days, which cured the urinary infection.

The patient also mentioned that her husband, aged 59 years, had had two "bad" attacks of prostatitis 4 years and 15 years previously. He had been treated with long courses of antibiotics, following which he recovered clinically.

Four weeks after the patient had attended the clinic her husband developed another attack of prostatitis, in the form of shivering, fever, an uncomfortable sensation of heat in the perineal region and thighs, and very painful terminal dysuria. He was seen by his general practitioner who referred him to another hospital. An MSU showed growth of $E$. coli with the same antibiogram as that isolated from his wife. He was treated with cephradine $500 \mathrm{mg}$ t.d.s. for 6 weeks. A rectal examination and CT performed on him in another hospital showed enlargement of the prostate consistent with prostatitis. (CT was done to exclude malignancy). One week after finishing the antibiotic course he presented to the Urinary Infection Clinic with painful dysuria and suprapubic pain. On examination he was not febrile, with mild suprapubic tenderness. Appropriate urine specimens were taken sequentially (urethral washout, MSU, prostatic secretion, urethral washout) ${ }^{4}$ which showed high numbers of white cells, which were much higher in the prostatic secretion. Culture demonstrated significant growth of $E$. coli from both bladder urine and prostatic secretion. This strain was compared with the one isolated from his wife, and was found to be identical according to the antibiogram, biotype, ${ }^{5}$ and serotype (06)-E. coli isolated from the stools of both patients were not of serotype 06.

In view of the recurrent episodes of cystitis the wife was put on long-term low dose chemoprophylaxis (250 $\mathrm{mg}$ cephradine at night). Since that time she has been asymptomatic for three months. The husband was 
treated with a 4 week course of ciprofloxacin $500 \mathrm{mg}$, 12 hourly. ${ }^{6}$

\section{Discussion}

The infecting organism $(E$. coli $)$ isolated from both the wife's and husband's urine and his prostatic fluid were of the same type, indicating that this infection was transmitted sexually from one to the other. In view of the history that the husband had had his prostatitis many years prior to their marriage, that is, much longer than their marriage, it seems probable that he transmitted the infecting organism to his wife rather than vice versa.

\section{References}

1 Vosti K. Recurrent urinary tract infections. JAMA 1975;231: 934-9.

2 Bailey RR, Peddie BA, Swainson CP, Kirkpatrick D. Sexual acquisition of urinary tract infection in a man. Nephron, 1986;44:217-8.

3 Wong ES, Stamm WE. Sexual acquisition of urinary tract infection in a man. JAMA 1983;250:3087-8.

4 Meares EM, Stamey TA. Bacteriologic localization patterns in bacterial prostatitis and urethritis. Invest Urol 1968;5:492-519.

5 Gargan R, Brumfitt W, Hamilton-Miller JMT. A concise biotyping system for differentiating strains of Escherichia coli. J Clin Pathol 1982;35:1366-9.

6 Gombert ME, de Bouchet L, Aulicino TM, Berkowitz LB, Macchia RJ. Prostatic concentrations of ciprofloxacin after oral administration. Am J Med 1987;82 (Suppl 4A):130-2. 